R. Q. Twiss (also of the Services Electronics Research Laboratory), who illustrated forward thinking by discussing the prospects of developing and detecting sub-millimetre waves; he gave special attention to the use of electrons travelling at approximately the speed of light. Mr. G. Knott (Mullard Research Laboratories) described the action of travelling-wave amplifiers and of backward-wave oscillators. In the first part of his discourse he referred particularly to the problem of noise in signal amplifiers and to the yet unsolved problems of mechanical design; in the second part he sketched the theory of backwardwave valves and described results achieved at a wave-length of about $2 \mathrm{~cm}$. which may lead to a new generation of low-power micro-wave oscillators.

The school then turned its attention to the important subject of reliability in electronic devices, and on this subject an address was given by $\mathrm{Mr}$. E. G. Rowe (Standard Telephones and Cables, Ltd.). Mr. Rowe explained what steps had been taken since 1945 to improve the general reliability of valves and described the problems which still remained to be solved. He was followed by Mr. G. H. Metson (Research Station of the General Post Office), who dealt specifically with the problem of designing valves for lives of the order of a hundred thousand hours (more than eleven years) and gave a scientific explanation of the factors determining long life in cathodes. In the morning a demonstration was given of millimetre-wave generators, and in the afternoon Mr. P. Gurnell superintended a demonstration of receiving-valve manufacturing techniques. The day closed with a lively discussion of how best to teach at university standard so as to obtain industrial scientists having a real understanding of scientific problems.

On September 22 the school transferred to Harlow, where it was addressed by Dr. D. A. Wright (Research Laboratories of the General Electric Co., Ltd.) and later by Mr. C. P. Lea-Wilson (Harlow) on the subject of thermionic cathodes. Dr. Wright described all types of thermionic emitter, dealing particularly with the limitations of the oxidecoated cathode, while Mr. Lea-Wilson paid special attention to high-temperature sintered cathodes used in magnetrons and high-power klystrons. Mr. J. Pollard (Services Electronics Research Laboratory) then discussed methods of obtaining high vacua and explained that the needs of the valve engineer are not yet adequately met either as regards speed of pumping or as regards ultimate vacua. In the afternoon Mr. J. E. Stanworth (British Thomson-Houston Research Laboratory) described the problems arising in the manufacture of glass and ceramic valve envelopes. In the second part of his address he dealt specifically with some of the new and interesting glasses developed recently. In the evening $\mathrm{Mr}$. A. Monk (Harlow) supervised a demonstration of the use of new materials in valve making.

The final day of the school was devoted to problems arising in connexion with solid-state devices. The introductory discourse was given by Mr. I. M. Ross (Services Electronics Research Laboratory), who surveyed the whole field, giving examples of entirely new solid-state devices which have come to light during the past few years. He was followed by Mr. E. H. Cooke-Yarborough (Atomic Energy Research Establishment), who described the properties of transistors and some of the uses to which they are being put. He emphasized that the transistor is a new type of electronic device in many ways utterly dissimilar to a valve and demonstrated some of the surprising circuits in which transistors can be used. Mr. E. B. Callick (Royal Naval Scientific Service) then discussed the problems encountered in manu. facturing transistors and emphasized that these represent an entirely new development in manufac. turing methods, where extremely minute traces of impurity are of primary importance and where the physical magnitudes involved are very small indeed. In the afternoon Mr. A. F. H. Thomson (Harlow) described the various types of memory or storage devices which are coming into use, taking the view that magnetic materials will play an ever-increasing part in this field. He was followed by Mr. P. E. Trier (Mullard Research Laboratories), who dealt, more specifically with magnetic switching devices. He showed how these can be built up into a full-scale computer and gave special attention to the difficult scientific problems which have yet to be solved in connexion with the use of ferro-magnetic materials and ferrites. During the afternoon a demonstration was given of solid-state devices in use in various ways.

In the short time which remained for discussion it was suggested that the proceedings of the school should be made available, at least in an abridged form, and it is hoped to publish these in the Journal of Electronics early next year.

J. THOMSON

\section{ANIMAL MOVEMENT}

$\mathrm{D}$

URING the British Association meeting at Bristol, Sections D (Zoology) and I (Physiology) held a joint session on September 6, at which the subject of "Animal Movement" was discussed. The first paper was by M. A. Sleigh, speaking on ciliary movement, and in it he gave an account of his own work on the movement of the peristomial cilia of Stentor. He suggested that the frequency of beat is a measure of the mechanical activity and that wave velocity is a measure of the metachronal co-ordination. Experiments have shown that the beat frequency and wave velocity have different temperature coefficients. Also it can be demonstrated that changes in the viscosity of the medium and in the viscosity of the protoplasm affect only the frequency and not the wave velocity, while the wave velocity can be substantially altered by digitoxin without appreciably affecting the frequency. The conclusion to be drawn is therefore that the two parts of the system are separate and have very different properties. Mr. Sleigh holds the view that the frequency might be maintained by the first cilium in a row acting as a pace-maker, while the excitation pathway of the wave velocity might be neuroid.

The second paper, by Dr. T. Weis-Fogh, was on the flapping flight of insects, and was illustrated by a slow-motion film on the flight of the desert locust. He described the wing movements in detail, and explained how the film was made and how his co-worker, Dr. Martin Jensen, had used it for estimating the changes both in magnitude and direction of the aerodynamic forces during the beat cycle. It has become clear that the wing cycle can be treated as a series of stationary flow situations and that the torques set up at the wing base can be estimated. When these torques are considered in detail, it is possible to subdivide them into aerodynamic and inertial torques, and to relate them to the torqueproducing components within the body. From this 
analysis, it is evident that the inertial torques are almost balanced by elastic torques arising from deformations of the body cuticle. When the various torques are summed for different phases of the beat, the result equals the torque which the flight muscles must produce. It appears that some two-thirds of the work is being expended against aerodynamic forces, and that the mechanical efficiency of the muscle system is 17-18 per cent.

The third speaker, Dr. R. H. J. Brown, discussed the flapping flight of birds. $\mathrm{He}$ pointed out that there are several different types of flapping movements, and that these are found either in different birds or in the same bird in different situations. The various types of flapping cycle were illustrated by lantern slides, and the functional differences between the various phases were described. It is clear that whereas the down-strokes are almost the same for all birds, the up-strokes may be entirely different both in path and function. These various types of up-stroke are found, with few exceptions, to be related to the size of the bird. The small birds up to the size of a pigeon usually fold their wings entirely during the up-stroke in slow flight. The pigeon and birds of similar size use a propulsive up-stroke in slow flight and a passive one in fast flight; and in the large species the up-stroke is passive except perhaps just before landing. Individual flight habit makes the transition point from one type to the other indefinite. It can be shown that these differences are to be expected from considerations of muscle weight, wing area and wing mass (inertia). While the qualitative picture is fairly clear, there is little information from which any quantitative estimates of aerodynamic or overall efficiency can be made.

The last paper was given by Dr. O. C. J. Lippold, who considered fatigue in human voluntary muscle. He suggested that the fatigue may be attributable to one or more of four factors: first, the voluntary drive may be diminished; secondly, the nerve conduction may be impaired; thirdly, the neuromuscular junction may be fatigued; and finally, the contractile mechanism may itself become weaker. It is probable that three of these factors are responsible for the diminished activity in fatigue, and that the main effect is due to one or other in different circumstances. For example, prolonged work, not of a strenuous nature, undoubtedly gives rise to central fatigue; but if a strong enough motive arises, the muscle activity can be restored to the unfatigued level. To what extent the occurrence of a neuromuscular block is important has not been settled, although experiments described by Dr. Lippold lead him to believe that such fatigue does not occur. He also holds the view that fatigue of the neural pathway is not a factor. On the other hand, under conditions of strenuous exercise it is clear that the fatigue can be predominantly muscular, and that the onset of fatigue is accelerated and the recovery delayed by impairment of the blood supply to the muscle. Finally, Dr. Lippold suggested methods by which the blood supply to the muscle might be increased, and thus postpone the onset of fatigue.

During the short discussion which followed, $\mathrm{Mr}$. Sleigh was questioned on his suggestion of a neuroid control in ciliary movement and pointed to the structures associated with cilia as supporting his views, and then Dr. Weis-Fogh explained some of his estimates of internal work and power losses in locust flight.

\section{STANDARDS IN BRITISH INDUSTRY}

TN two recent broadsheets (Nos. 381 and 382, July 11, 1955) Political and Economic Planning reviews the various types of standards in use in British industry, examines the arguments for and against their use and scrutinizes the work of the British Standards Institution; in particular, the method of preparing standards and the extent to which they are adopted are considered, and whether the Institution, as at prosent constituted, is capable of doing justice to its growing responsibilities at home and overseas.

Industrial standards fall into two broad categories : functional standards, or the tools used in doing a job; and dimensional standards which, by laying down dimensions and tolerances for finished and semi-finished goods, secure interchangeability and simplification. Frequently there are combinations of both types. Britain's leadership in aircraft design has been helped considerably by the many standards relating to production, drawing-office practice and engineering construction, and objections to the use of standards in industry are often based on misconceptions of what standards imply. The first of these two broadsheets indicates the vital contribution which standardization can make to efficiency in industry by cutting out waste of machine-time, materials, power and labour, and also the importance of standards in foreign markets. Many problems are involved in the formulation of standards both tech. nically sound and commercially practicable, and the resolution of these difficulties in Great Britain falls to the British Standards Institution, which is the subject of the second broadsheet.

Essentially the British Standards Institution is a co-ordinating body bringing together the technical knowledge of those engaged in industry, professional associations, technical colleges, universities and government departments, and the practical and commercial knowledge of producers, distributors and consumers in an endeavour to produce standards acceptable to all interests concerned. Until 1931, its activities were mainly confined to the engineering industry; but in that year a Supplemental Royal Charter enlarged its terms of reference to user industry as a whole and its name was changed from British Engineering Standards Association to British Standards Institution. By 1939 it had grown to something like its present size and published nearly a thousand standards for a wide range of engineering and chemical, building and like materials. It has always worked for the promotion of British standards abroad, and continues to take an active part in the movement for internationally accepted standards. Between the two World Wars it became concerned with the standards since known as Codes of Practice, of which more than a hundred and fifty have been issued, ranging from the planning of buildings for ensuring adequate sunlight to the use of electronic valves.

The broadsheet suggests that the Institution could take a wider view of the whole question of standards, and that its work at home should follow some order of priority more closely related to the productive efficiency of the country as a whole. Closer co-operation between the Institution and the British Productivity Council in an effort to introduce standards, where they are likely to be of most benefit, is 